23

\title{
Спектры фотолюминесценции в поликристаллах хирально чистых и рацемической фаз триптофана
}

\author{
(C) В.С. Горелик ${ }^{1}$, М.Ф. Умаров ${ }^{2}$ \\ ${ }^{1}$ Физический институт им. П.Н. Лебедева РАН, \\ 119991 Москва, Россия \\ ${ }^{2}$ Вологодский государственный университет, \\ 160000 Вологда, Россия \\ e-mail: gorelik@sci.lebedev.ru
}

Поступила в редакцию 15.12.2017 г.

\begin{abstract}
Выполнено сопоставление спектров фотолюминесценции трёх кристаллических фазовых модификаций ароматической аминокислоты триптофана: левой фазы - L-триптофана, правой фазы - D-триптофана и рацемической фазы - DL-триптофана. Регистрация спектров фотолюминесценции была проведена с использованием волоконно-оптической методики, малогабаритного спектрометра типа FSD-8 и системы обработки данных, позволяющей провести сравнение анализируемого спектра со спектром эталонного вещества. Возбуждение фотолюминесценции осуществлялось импульсно-периодическим ультрафиолетовым лазером с длиной волны излучения $266 \mathrm{~nm}$.
\end{abstract}

DOI: $10.21883 /$ OS.2018.07.46280.297-17

\section{Введение}

Биоактивные препараты включают в себя большой класс веществ, оказывающих сильное воздействие на молекулярном уровне на биологические структуры и живые организмы. К ним относятся, в частности, аминокислоты, различные фармацевтические препараты, стимуляторы процессов жизнедеятельности, токсические вещества и др. Для эффективного использования биоактивных препаратов необходимо обеспечение соответствия их молекулярной структуры и состава номинальным препаратам, воздействие которых на биологические структуры и живые организмы надёжно установлено. Так как во всех протеиногенных аминокислотах (кроме глицина) имеется асимметричный $\alpha$-углеродный атом, молекулы аминокислот являются энантиоморфными, т. е. могут существовать в виде левой (L), правой (D) или рацемической (DL) формах $[1,2]$. Все естественные протеиногенные аминокислоты имеют L-конформацию. Аминокислоты D-конформации, как правило, живыми клетками не усваиваются. Продуктом химической реакции без участия какого-либо асимметричного агента, реагирующего на зеркальную асимметрию молекулы, является рацемическая фаза (DL-конформация) или смесь в равных концентрациях D- и L-конформаций. Присутствие в организме рацематов и правых (D) конформаций аминокислот приводит к нарушению процессов жизнедеятельности.

В связи с этим возникает задача выявления типа хирального состояния аминокислот для их практического использования при создании фармацевтических препаратов, при введении аминокислот в пищевые продукты в качестве биологически активных добавок и т.д. Для решения такой задачи могут быть использованы спектроскопические методы, включая фотолюминесцен- цию (ФЛ), метод комбинационного рассеяния света, нелинейно-оптическую спектроскопию и т. д. [3-5]. Для однозначного ответа на вопрос о степени соответствия молекулярной структуры и состава анализируемой аминокислоты, характеристики которой присутствуют в базе данных, необходимо провести на количественном уровне сравнение спектров различных модификаций триптофана.

В данной работе сообщается о волоконно-оптическом методе анализа спектров ФЛ поликристаллического триптофана, существующего в виде L-, D- и DL-модификаций.

\section{Методика эксперимента}

В качестве объектов исследования нами были выбраны поликристаллические образцы аминокислоты триптофана в виде L-, D- и DL-конформаций. Образцы были предоставлены фирмой „Roanal“ (Венгрия). В таблице приведены химические и структурные формулы исследованных фаз триптофана. Как видно из этой таблицы, в структуре обеих фаз триптофана присутствуют ароматические кольца, что приводит к фундаментальному электронному поглощению этих соединений в среднем ультрафиолетовом диапазоне. Соответственно в этих веществах наблюдается ФЛ в фиолетово-синем диапазоне при возбуждении образцов коротковолновым электромагнитным излучением.

Для возбуждения и регистрации спектров ФЛ использовалась волоконно-оптическая методика [6-10]. Принципиальная схема экспериментальной установки приведена на рис. 1. В качестве источника возбуждающего ультрафиолетового излучения использовалась четвёртая гармоника $(266 \mathrm{~nm})$ лазера на алюмоиттриевом гранате, генерирующего импульсно-периодическое излучение со 
Химические и структурные формулы триптофана

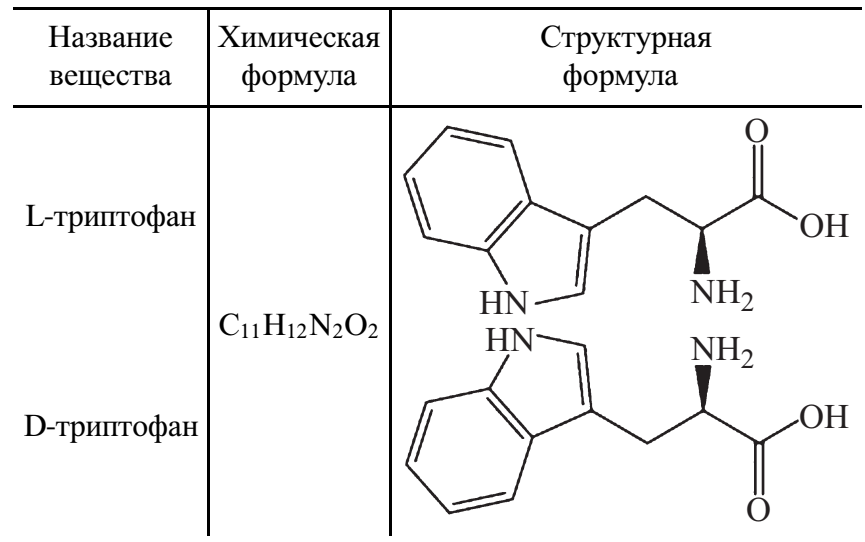

средней мощностью генерации $10 \mathrm{~mW}$, с частотой следования импульсов $3000 \mathrm{~Hz}$ при их длительности $10 \mathrm{~ns}$. Пиковая плотность мощности возбуждающего ультрафиолетового излучения на поверхности анализируемого препарата составляла $10^{4} \mathrm{~W} / \mathrm{cm}^{2}$. Анализируемое вещество в виде таблетки помещалось в кювету (рис. 1). Кварцевый световод использовался для подведения ультрафиолетового излучения к веществу и для отвода возникающего в анализируемой пробе люминесцентного излучения к малогабаритному спектрометру типа FSD-8. При этом пространственное разрешение на поверхности анализируемой пробы составляло $\sim 0.1 \mathrm{~mm}$. Используемый спектрометр позволял осуществлять регистрацию спектра ФЛ исследуемых веществ в диапазоне 200-1000 nm при экспозициях 0.01-0.1 s. От миниспектрометра FSD-8 цифровая информация о спектре ФЛ излучения передавалась на компьютер. После компьютерной обработки нами были построены нормированные спектры ФЛ триптофана.

\section{Результаты и их обсуждение}

На рис. 2 приведены спектры ФЛ L-, D- и DL-триптофана при возбуждении четвертой гармоники $(266 \mathrm{~nm})$ импульсно-периодического лазера на алюмоиттриевом гранате. Как видно из сравнения спектров ФЛ, представленных на рис. 2, максимум интенсивности ФЛ для L-триптофана соответствует $340.1 \mathrm{~nm}$, а соответствующий максимум интенсивности для D-триптофана $352.7 \mathrm{~nm}$. При этом максимум интенсивности ФЛ для DL-триптофана соответствует $388.0 \mathrm{~nm}$, т.е. полоса ФЛ DL-триптофана существенно сдвинута в сторону больших длин волн по отношению к L- и D-триптофану. Наблюдаемая спектральная полуширина полосы ФЛ для DL-триптофана составляет $94 \mathrm{~nm}$, т.е. на $48 \mathrm{~nm}$ больше соответствующего значения для L-триптофана и на $31 \mathrm{~nm}$ больше соответствующего значения для D-триптофана, интенсивность максимума ФЛ DL-триптофана в сравнении с L-триптофаном составляет $1: 15$, в то время как для D-триптофана эта величина составляет 1:25.
Форма полосы DL-триптофана существенно отличается от формы соответствующей полосы хирально чистых фаз.

Существует несколько способов сравнения спектров вторичного излучения веществ: метод наименьших квадратов [11], метод функций корреляции спектров [12-15] и др. Остановимся на описании способа, основанного на построении разностных спектров, задаваемых с помощью распределения интенсивности спектра в нормированном цифровом виде. При этом рассчитываются разностные нормированные спектры вторичного излучения [16-20] на основе следующего соотношения:

$$
K_{A}^{E}(\lambda)=1-\left|I_{A}(\lambda)-I_{E}(\lambda)\right|
$$

Здесь $I_{A}(\lambda), I_{E}(\lambda)$ - нормированные спектры вторичного излучения анализируемого вещества $(A)$ и эталонного вещества $(E)$. Для анализа спектров используется так

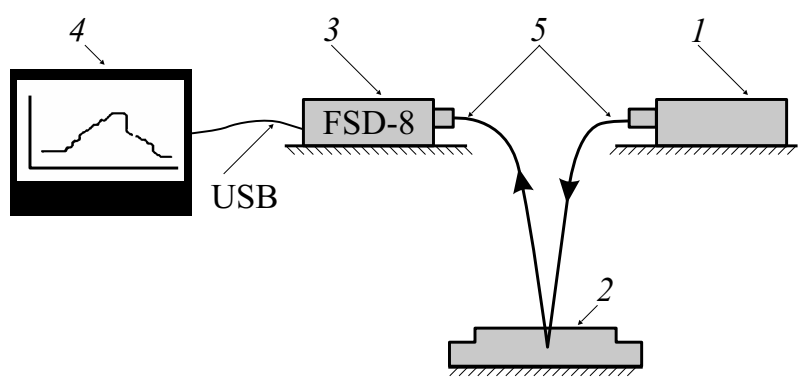

Рис. 1. Схема экспериментальной установки для регистрации спектров ФЛ на отражение: 1 - источник излучения (лазер, $266.0 \mathrm{~nm}), 2$ - кювета с образцом, 3 - миниспектрометр FSD-8, 4 - персональный компьютер, 5 - кварцевый световод.

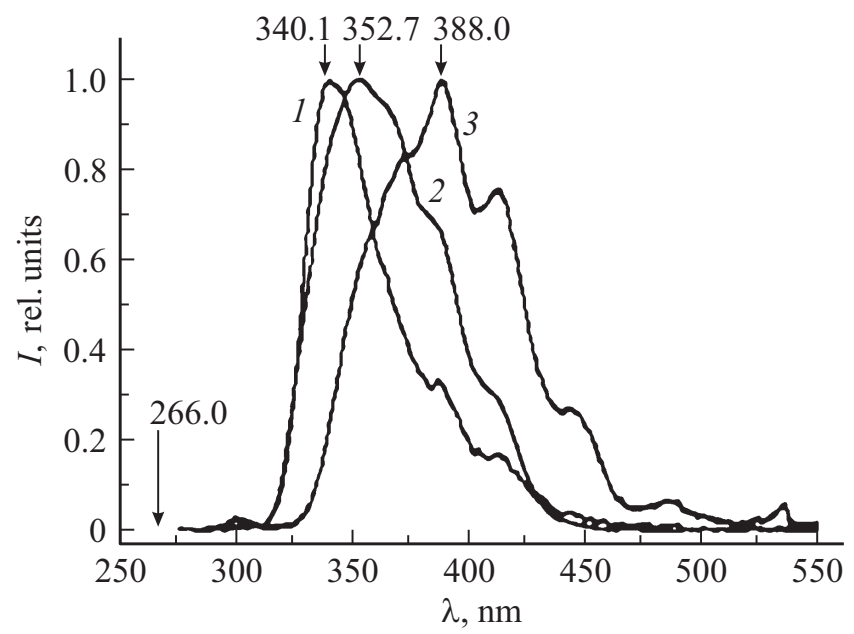

Рис. 2. Спектры ФЛ L-триптофана (1), D-триптофана (2) и DL-триптофана (3) при возбуждении импульсно-периодическим лазерным излучением с длиной волны $266.0 \mathrm{~nm}$ при комнатной температуре. Стрелками отмечены спектральные положения максимумов ФЛ. 

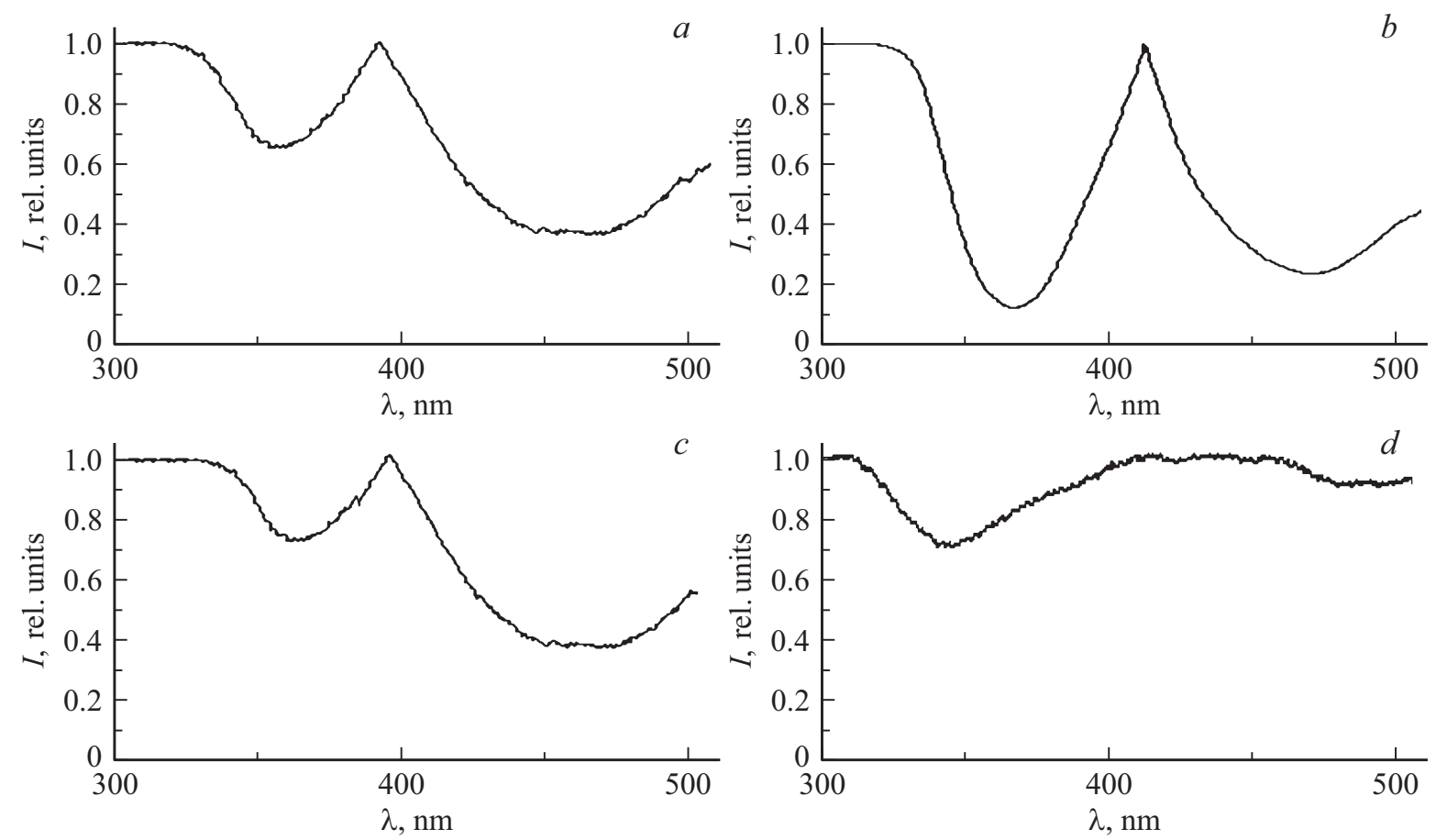

Рис. 3. Разностные спектры $\left(a-\mathrm{L}\right.$-триптофан при сравнении с D-триптофаном, коэффициент соответствия $K_{D}^{L}=0.84 ; b-$ $\mathrm{L}$-триптофан при сравнении c DL-триптофаном, коэффициент соответствия $K_{D L}^{L}=0.58 ; c-\mathrm{D}$-триптофан при сравнении с DL-триптофаном, $K_{D}^{D L}=0.66 ; d-$ D-триптофан при сравнении с разными образцами D-триптофана, $\left.K_{D}^{D}=0.94\right)$.

называемый коэффициент соответствия $K$ :

$$
K=\frac{\sum_{i=1}^{N}\left(1-\left|I_{A}(\lambda)-I_{E}(\lambda)\right|\right)_{i}}{N} .
$$

Здесь $\mathrm{N}$ - число точек, для которых получены цифровые данные о спектре ФЛ.

Для аналитического сравнения спектров ФЛ L-, Dи DL-триптофана были построены разностные функции с использованием соотношения (1). Соответствующие спектры приведены на рис. $3, a-d$. Разностные спектры строились в диапазоне длин волн $\Delta \lambda=300-500 \mathrm{~nm} \mathrm{c}$ интервалом разбиения $\Delta \lambda_{i}=0.25 \mathrm{~nm}$. Кроме того, на основе соотношения (2) были вычислены соответствующие коэффициенты соответствия $(K)$, которые приведены в подписях к рис. $3, a-d$.

Как видно из рис. $3, a-d$, разностные спектры и коэффициенты соответствия позволяют установить степень сходства между различными модификациями аминокислоты триптофана. Следует отметить, что так как спектры ФЛ L- и D-триптофана мало отличаются друг от друга (рис. $3, a, b)$, коэффициент соответствия $K_{D}^{L}=0.84$, т. е. ближе к единице по сравнению со спектрами ФЛ Lи DL-триптофана (рис. 3, $a, c$ ), где коэффициент соответствия $K_{D L}^{L}=0.58$. Для идентичных структур коэффициент соответствия близок к единице (рис. $3, d$ ), где коэффициент соответствия при сравнении D-триптофана с разными образцами D-триптофана $K_{D}^{D}=0.94$. При совпадении спектров анализируемых объектов коэффициент соответствия равен единице.
Отметим, что, как видно из рис. 2, наблюдается отличие спектров ФЛ D- и L-триптофана, т. е. правой и левой форм триптофана. Нарушение закона зеркальной симметрии в спектрах левой и правой форм представляет принципиальный интерес [21]. Надежное установление такой закономерности требует дополнительных исследований. Более простое объяснение наблюдаемых отличий в спектрах исследованных образцов D- и Lтриптофана состоит в возможности недостаточной хиральной чистоты анализируемых объектов и присутствия в них небольшого количества рацемата (D- и L-фаз). Таким образом, на основе анализа спектров ФЛ твердотельных ароматических аминокислот может быть установлена степень их хиральной чистоты на количественном уровне.

Наблюдаемое отличие спектров ФЛ хирально чистых фаз от рацемата можно объяснить тем, что центросимметричная кристаллическая структура DL-триптофана существенным образом отличается от нецентросимметричной кристаллической структуры D- и L-триптофана. Молекулярное взаимодействие между зеркально симметричными молекулами в рацемической фазе приводит к изменению вида соответствующих электронных спектров. Это может быть причиной наблюдаемых в спектрах ФЛ сдвигов положений максимумов и уширения полос.

В случае рацемата спектр ФЛ существенно сдвигается в длинноволновую область и уширяется. С другой стороны, наблюдаемый эффект различия в спектрах хирально чистых фаз и рацемата может быть использован для 
анализа хиральной чистоты промышленных препаратов, широко используемых в настоящее время для ускорения роста биомассы животных. Присутствие в пище правых изомеров триптофана, а также рацематов, входящих в состав белков и биологически-активных сред, может приводить к патологии потребителей таких продуктов.

\section{Заключение}

Таким образом, в данной работе на примере ароматических аминокислот триптофана установлено отличие спектров ФЛ D- и L-триптофана, т.е. правой и левой форм триптофана. Нарушение закона зеркальной симметрии в спектрах ФЛ левой и правой форм триптофана представляет принципиальный интерес. Возможно, наблюдаемые различия в спектрах ФЛ левой и правой форм триптофана связаны с особенностями их приготовления и присутствия различных примесей, возникающих в процессе роста поликристаллов. Для надежного установления такой закономерности необходимо провести аналогичные исследования с другими образцами поликристаллического триптофана, а также с другими ароматическими аминокислотами: тирозином и фенилаланином. Возбуждение спектров ФЛ осуществлялось четвертой гармоникой лазера на алюмоиттриевом гранате с использованием волоконно-оптического зонда и малогабаритного светосильного спектрометра. Разработанная методика обеспечивает получение экспрессинформации от небольшого количества анализируемой пробы с высоким пространственным разрешением по поверхности образца $0.1 \mathrm{~mm}$ при времени экспозиции, равном $0.01-0.1 \mathrm{~s}$.

Известно, что при добавлении в комбикорм аминокислоты триптофана происходит набор мышечной массы у скота и птиц, а также накопление этой аминокислоты в организме животных. Потребление при этом правой или рацемической форм триптофана может привести к патологиям в организме и нарушению процессов метаболизма у животных, а также во всей цепочке организмов, в которые попадают правые или рацемические фазы аминокислот. Предлагаемый метод выявления хирально чистых протеиногенных аминокислот может быть полезен для сохранения хиральной чистоты биологически активных веществ и живых организмов.

Работа выполнена при частичной поддержке РФФИ (грант 18-02-00181-a).

\section{Список литературы}

[1] Горелик В.С., Нечаева Е.Ю. // Краткие сообщения по физике ФИАН. 2010. Т. 37. № 5. С. 52; Gorelik V.S., Nechaeva E.Y. // Bulletin of the Lebedev Physics Institute. 2010. V. 37. N 5. P. 157.

[2] Белянчиков М.А., Горелик В.С., Горшунов Б.П., Пятышев А.Ю. // ЖЭТФ. 2017. Т. 151. № 1. С. 90.

[3] Gorelik V.S., Rakhmatullaev I.A. // Inorganicmaterials. 2004. V. 40. N 7. P. 686.
[4] Downesand A., Elfick A. // J. Sensors. 2010. V. 10. N 3. P. 1871.

[5] Sikirzhytski V., Virkler K., Lednev I.K. // J. Sensors. 2010. V. 10. N 4. P. 2869.

[6] Войнов Ю.П., Горелик В.С., Умаров М.Ф., Морозова С.B. // Краткие сообщения по физике ФИАН. 2011. T. 38. № 11. C. 13; Voinov Y.P., Gorelik V.S., Umarov M.F., Morozova S.V. // Bulletin of the Lebedev Physics Institute. 2011. V. 38. N 11. P. 328.

[7] Войнов Ю.П., Горелик В.С., Пятышев А.Ю., Умаров М.Ф. // Краткие сообщения по физике ФИАН. 2012. T. 39. № 12. C. 28; Voinov Y.P., Gorelik V.S., Pyatyshev A.Y., Umarov M.F. // Bulletin of the Lebedev Physics Institute. 2012. V. 39. N 12. P. 341.

[8] Горелик В.С., Литвинова Ф.О., Умаров М.Ф. // Краткие сообщения по физике ФИАН. 2014. Т. 41. № 11. С. 3; Gorelik V.S., Litvinova A.O., Umarov M.F. // Bulletin of the Lebedev Physics Institute. 2014. V. 41. N 11. P. 305.

[9] Умаров М.Ф., Горелик В.С. Оптическая спектроскопия биоактивных препаратов / Монография. Вологда: ВоГУ, 2014. $147 \mathrm{c}$.

[10] Войнов Ю.П., Горелик В.С., Умаров М.Ф., Юрин М.Е. Патент РФ № 2488097, 2013.

[11] Глаголев К.В., Голяк И.С., Голяк И.С., Есаков А.А., Корниенко В.Н., Кочиков И.В., Морозов А.Н., Светличный С.И., Табалин С.Е. // Опт. и спектр. 2011. Т. 110. № 3. C. 486; Glagolev K.V., Golyak Ig.S., Golyak Il.S., Esakov A.A., Kornienko V.N., Kochikov I.V., Morozov A.N., Svetlichnyi S.I., Tabalin S.E. // Opt. Spectrosc. 2011. V. 110. N 3. P. 449.

[12] Глаголев К.В., Морозов А.Н., Назаренко Б.П., Табалин С.Е., Чубурков О.В., Светличный С.И., Никитаев С.П., Рожнов А.В., Филиппов В.И., Григорьев А.А. // Вестник МГТУ им. Н. Э. Баумана, серия Естественные науки. 2005. № 3. С. 9.

[13] Бойко А.Ю., Григорьев А.А., Мащюк Г.В., Павлов А.Ю., Шлыгин П.Е., Дворук С.К., Лельков М.В., Морозов А.Н., Табалин С.Е., Шишкин Г.В., Корниенко В.Н., Кочиков И.В., Светличный С.И. // Вестник МГТУ им. Н.Э. Баумана, серия Естественные науки. 2004. № 1. С. 26.

[14] Дворук С.К., Корниенко В.Н., Кочиков И.В., Лельков М.В., Морозов А.Н., Светличный С.И., Табалин С.Е. // Оптический журнал. 2004. Т. 71. № 5. С. 7.

[15] Морозов А.Н., Светличный С.И., Фуфурин И.Л. // Вестник МГТУ им. Н.Э. Баумана, серия Естественные науки. 2007. № 2. C. 3.

[16] John G. Duguid, Victor A. Bloomfield, James M. Benevides, George J. Thomas // Biophysical J. 1996. V. 71. N 6. P. 3350.

[17] Langlais M., Tajmir-Riahi H.A., Savoie R. // Biopolymers. 1990. V. 30. N 7. P. 743.

[18] Kint S., Tomimatsu Y. // Biopolymers. 1979. V. 18. N 5. P. 1073.

[19] Benevides J.M., Overman S.A., Thomas G.J. // J. Raman Spectroscopy. 2005. V. 36. N 4. P. 279.

[20] Бортников К.С., Горелик В.С., Есаков А.А. // Неорганические материалы. 2007. Т. 43. № 12. С. 1458; Bortnikov K.S., Gorelik V.S., Esakov A.A. // Inorganic Materials. 2007. T. 43. N 12. C. 1313.

[21] Хриплович И.Б. Несохранение четности в атомных явлениях. М.: Наука, 1988. 288 с. 